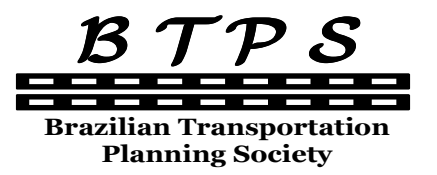

Planning Society
Journal of Transport Literature

Vol. 7, n. 1, pp. 83-102, Jan 2013

Research Directory
JTL | RELIT

www.transport-literature.org ISSN 2238-1031

\title{
A entrada dos veículos comerciais leves chineses: uma ameaça à hegemonia das grandes marcas?
}

[The entry of the chinese light commercial vehicles: a threat to the hegemony of the dominant companies?]

\author{
Thiago Vinicius Alves Ueda* \\ Instituto Tecnológico de Aeronáutica (ITA), Brazil
}

Submitted 1 Aug 2011; received in revised form 3 Jan 2012; accepted 26 Jan 2012

\begin{abstract}
Resumo
Este artigo tem como objetivo avaliar as perspectivas do mercado brasileiro de autoveículos, com ênfase na classe de veículos comerciais leves (VCL). 0 segmento caracterizou a porta de entrada que possibilitou a internacionalização das marcas chinesas em meados de 2006. 0 estudo econométrico demonstra que a frota brasileira contará com mais um milhão e duzentos mil veículos desta categoria o que, em termos percentuais representa um crescimento de $6 \%$ anualmente. 0 volume de vendas de VCL chineses tem evoluído a taxas consideravelmente mais elevadas, da ordem de $450 \%$ a.a., superior inclusive à média de crescimento das rivais coreanas. Além disso, fornece embasamento para o fomento de políticas públicas acerca do planejamento de transportes urbano e emissões veiculares de poluentes nos grandes centros.
\end{abstract}

Palavras-Chave: veículos comerciais leves; estudo econométrico; marcas chinesas; liberalização.

\begin{abstract}
This paper has the objective to evaluate perspectives of the Brazilian auto market post-liberalization to imports in the 1990s, with emphasis in the sector of light commercial vehicles (LCV). The segment was the entrance door that allowed the internationalization of Chinese companies in mid-2006. The econometric study demonstrates that the Brazilian fleet will include over one million and two thousand vehicles in this category that in percentage terms represents a annual growth of $6 \%$. The volume of sales of Chinese LCV has evolved to substantially higher rates of the order of $450 \%$ per year higher than the average growth rate of the Koreans rivals. In addition, it provides scientific foundation for the promotion of public policies on urban transport planning and vehicle emissions of pollutants in great urban centers.
\end{abstract}

Key words: light commercial vehicles; econometric study; Chinese companies; liberalization.

*Email: uedathiago@gmail.com.

\section{Recommended Citation}

Ueda, T. V. A. (2013) A entrada dos veículos comerciais leves chineses: uma ameaça à hegemonia das grandes marcas?. Journal of Transport Literature, vol. 7, n. 1, pp. 83-102.

- JTL/RELIT is a fully electronic, peer-reviewed, open access, international journal focused on emerging transport markets and published by BPTS - Brazilian Transport Planning Society. Website www.transport-literature.org. ISSN 2238-1031.

This paper is downloadable at www.transport-literature.org/open-access. 


\section{Introdução}

Este artigo tem como objetivo avaliar as perspectivas do mercado brasileiro de autoveículos, com ênfase na classe de veículos comerciais leves (VCL). Do ponto de vista das políticas públicas, há relevância no estudo desta classe, em especial, pois compõe um setor que está em franca ascensão, e num futuro próximo pode tornar-se um gargalo para as infraestruturas viárias e seus desdobramentos. Portanto, fornece embasamento para o fomento de políticas públicas acerca do planejamento de transportes urbano e emissões veiculares de poluentes nos grandes centros.

Entende-se por comerciais leves a classe de todos os veículos que possuem peso bruto total, de até 3,5 toneladas. Englobam desde as pick-ups pequenas, derivadas dos utilitários de passeio - setor pioneiro indústria brasileira - até os furgões, vans, e utilitários esportivos. $\mathrm{Na}$ maioria dos casos, esta classe de veículos é utilizada como ferramenta de trabalho, por isso deve apresentar excelente relação custo-benefício, baixa necessidade de manutenção e tratamento diferenciado no pós-venda. O segmento caracterizou a porta de entrada que possibilitou a internacionalização das marcas chinesas em meados de 2006.

O presente estudo estima que a frota brasileira contará com mais um milhão e duzentos mil veículos desta categoria - o que, em termos percentuais representa um crescimento de $6 \%$ anualmente. $\mathrm{O}$ volume de vendas de VCL chineses tem evoluído à taxas mais elevadas, da ordem de $450 \%$ aa, superior a média de crescimento das rivais coreanas.

O mercado brasileiro de autoveículos possui notoriedade no contexto internacional. No ranking mundial, ocupa a sexta colocação em produção e a quinta posição em vendas. O setor automobilístico nacional caracteriza-se por um oligopólio entre oito empresas dominantes: Chevrolet, GM (General Motors), Ford, Volkswagen, Fiat, Toyota, Honda, Renault e Peugeot-Citroen. Nos últimos anos a Fiat, Volkswagen (VW) e a GM vem mantendo a liderança das vendas, possuindo em média mais de $75 \%$ do mercado, justificada pela produção dos modelos populares mais vendidos no Brasil: VW Gol, Fiat Palio, Fiat Uno, GM Celta e VW Fox, em conformidade aos levantamentos da ANFAVEA (2010). 
A dimensão atual do setor foi estabelecida em grande parte pela liberalização das importações na década de 90, acompanhada por uma redução nas alíquotas dos impostos, possibilitando a entrada de modelos importados no mercado brasileiro (Fiúza, 2002). Conjuntamente, o Plano Real exerceu grande influência no mercado automotivo ao proporcionar estabilidade de preços, disponibilidade de crédito, e incentivo ao consumo de bens duráveis. Neste mesmo período, firmaram-se diversos acordos visando desenvolver o parque industrial automobilístico nacional e estreitar as relações de comércio exterior: majoritariamente acordos bilaterais no MERCOSUL. Podemos citar o acordo Automotivo de 1993 que promoveu o fomento ao "carro popular" e ocasionou um "boom" nas vendas internas. Com um bônus tributário e a expansão creditícia para potenciais consumidores das classes de renda mais baixa nos anos posteriores, a demanda por carros da categoria 1.0 foi a que mais cresceu.

Recentemente, o Brasil tem adotado medidas de retaliação à Argentina que consistem no retardo do procedimento de licença não automática para veículos importados devido ao fato deste país ter adotado medidas protecionistas contra produtos brasileiros contrariando acordos bilaterais.

Por outro lado, o Regime Automotivo de 1995 desonerou as tarifas de importação e promoveu benefícios fiscais para que as empresas instaladas no Brasil mantivessem suas plantas e novas empresas começassem a produzir em território nacional. Tais medidas visavam não só ao incentivo do consumo interno como à aceleração na geração de empregos e desenvolvimento regional. Na segunda metade da década de 1990, houve a instalação de diversas montadoras no país e a modernização das plantas para as empresas aqui instaladas previamente ao regime, conferindo mais diversidade e dinamismo ao mercado brasileiro.

As crises financeiras internacionais, da segunda metade dessa década, afetaram a balança de pagamentos brasileira e as contas fiscais do governo, colocando em ameaça a oferta dos incentivos tributários. Por exemplo, a crise asiática refletiu fortemente no lado fiscal e o governo sentiu-se pressionado a elevar a receita tributária, refletindo em aumentos nas alíquotas sobre os automóveis. As vendas declinaram e só se reverteram após os novos acordos assinados em 1998 e 1999 que promoveram uma reforma na estrutura tributária setorial. 
Outro mecanismo de incentivo ao setor de automóveis faz menção ao regime automotivo especial para as regiões Norte, Nordeste e Centro-Oeste que existe desde dezembro de 1996, tendo como objetivo promover a descentralização da indústria automotiva. A fim de aproveitar os benefícios, a Ford instalou uma fábrica na Bahia e a Caoa, que fabrica automóveis Hyundai e Mitsubishi, implantou uma matriz de produção em Goiás. Recentemente, o governo federal estendeu, até 2020, este regime tributário especial para as montadoras de veículos e as fabricantes de autopeças. Este incentivo fiscal é válido apenas para firmas instaladas previamente a extensão do prazo, portanto não beneficiará novas empresas que ambicionam entrar no mercado brasileiro, como as montadoras coreanas e chinesas. Estimativas da FIEB (2010) avaliam que esta iniciativa governamental renunciará tributos da ordem de R 4,534 bilhões até 2014.

Em síntese, a visão panorâmica do mercado brasileiro de autoveículos fornece indícios do potencial de crescimento, seja pelos incentivos governamentais, pela entrada massiva dos fabricantes asiáticos, em especial, os chineses, ou pela reorganização da indústria automobilística mundial que visa transferir as funções de produção e consumo para os países emergentes, tais como China, Índia e Brasil.

O presente trabalho está assim dividido: na Seção 1, aborda-se o mercado brasileiro de autoveículos no contexto pós-liberalização e são fornecidas explanações acerca dos incentivos fiscais governamentais. Na Seção 2, apresenta-se o processo de introdução das marcas estrangeiras. A seção 3 sistematiza o segmento brasileiro de veículos comerciais leves e aborda as especificidades dos veículos comerciais leves chineses. Na seção 4, apresenta-se o estudo econométrico de previsão de unidades de veículos comerciais leves comercializados nos anos de 2011 e 2012. E por fim, nas Conclusões, estrutura-se uma perspectiva para a entrada das marcas chinesas no mercado brasileiro. Os resultados apontam que a entrada das marcas chinesas será massiva e será favorecida pelas subvalorizadas taxas de câmbio brasileiras e chinesas. 


\section{A ameaça às grandes montadoras}

A introdução das marcas estrangeiras foi cautelosa, hoje, no entanto a participação dos importados vem crescendo a cada ano. Eles já respondem por $22 \%$ das vendas, participação que era de 4\% em 2004, segundo dados da ABEIVA (2010). Este aumento participativo real concorda com as previsões de market share das montadoras no mercado autoveicular nacional apresentadas pela CSM Worldwide. A tabela abaixo proporciona uma ideia das participações de mercado das montadoras.

Tabela 1 - Previsão de market share das montadoras no Brasil. Fonte: CSM Worldwide (2010).

\begin{tabular}{l|ccc}
\hline Market Share & 2002 & 2008 & 2015 \\
& & & \\
\hline VW/Fiat/GM/Ford & $83 \%$ & $73 \%$ & $64 \%$ \\
Renault/Nissan/Peugeot & $8 \%$ & $14 \%$ & $15 \%$ \\
Montadoras Asiáticas & $7 \%$ & $10 \%$ & $20 \%$ \\
\hline
\end{tabular}

A maturação do mercado automotivo, e os incentivos fiscais oferecidos pelo governo, atraíram grandes marcas estrangeiras para implantar suas montadoras e concessionárias no território brasileiro. Estatísticas da FENABRAVE (2009) confirmam que a partir de 2008, houve uma gradual perda de mercado da Ford pela ascensão das marcas Honda, Renault, Peugeot, Citroen e Toyota.

Nos últimos anos, um processo análogo vem ocorrendo com a entrada efetiva das marcas chinesas no mercado brasileiro: Chana, Effa, Jimbei, Hafei, Chery, MG, Lifan e JAC e as entradas potenciais da: Haima, Brilliance, BYD, Great Wall, Geely e Shuanghuan Automobile, que não definiram data para começarem suas operações.

As firmas dominantes vêm perdendo, no momento, irrisórias fatias de mercado. Por exemplo, os principais modelos fabricados pelas quatro grandes montadoras brasileiras respondiam por 57\% das vendas internas em 2004. Em 2011, a participação conjunta destes seis modelos caiu para 36\% de janeiro a abril. Desde a liberalização às importações, em 1990, é a primeira vez 
que as quatro maiores fabricantes enfrentam essa concorrência. Um caso similar de ampla concorrência e perda de mercado se concretizaram no mercado norte americano após a liberalização à entrada das marcas japonesas. A Figura 1 mostra o declínio gradativo da participação das montadoras dominantes norte-americanas: Ford e GM, em contrapartida, nota-se um aumento substancial das fabricantes japonesas: Honda, Toyota e Nissan, que hoje competem no mercado em equidade.

Figura 1 - Participação de mercado (\%) das principais montadoras na indústria automobilística norte americana. Fonte: OICA (2010)

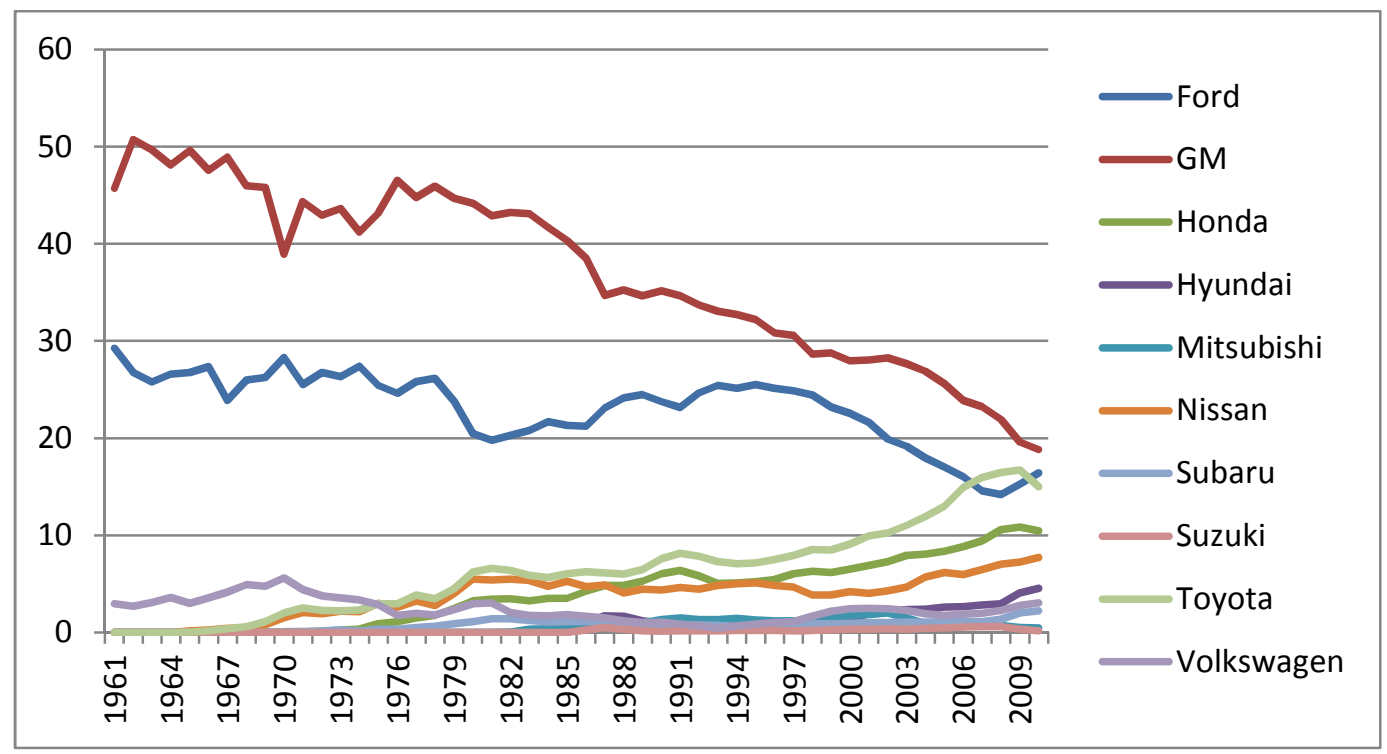

A ascensão da importação e comercialização de automóveis chineses indica o início da internacionalização que ocorreu semelhantemente às montadoras japonesas na década de 90 e coreanas, na primeira década deste século, obedecendo ao modelo sistêmico estrutural dos movimentos de internacionalização proposto pela Escola de Uppsala (U-model, 1975), afirma Vieira (2010). A China caminha para um desenvolvimento automotivo uma vez que pode valer-se da experiência nipônica anterior e da aquisição de empresas ocidentais para alcançar market shares cada vez mais significativos. 


\section{Segmento promissor: Veículos comerciais leves - VCL}

O segmento de transporte de carga e pessoas alterou-se na última década, surgindo espaço para furgões e vans. Os volumes de venda têm crescido no mercado interno e externo devido ao incremento do setor de prestação de serviços, agronegócio, pecuária e turismo. Não obstante isso, o número de consumidores que praticam esportes de aventura: rafting, canoagem, motocross, rallies, aumentou, portanto, a demanda de "picapes" cresceu.

Contata-se que o número de unidade de veículos comerciais leves (VCL) vendidas está positivamente correlacionado com a evolução do PIB nacional como indica a Figura 2. Concomitantemente, é possível detectar os efeitos da crise mundial de 2008-2009. Embora o Brasil não tenha sofrido altas penalizações no período de crise, a queda nas vendas pode ser explicada pela recessão econômica ocorrida nos países de origem das montadoras de automóveis.

Figura 2 - Correlação Positiva entre o PIB nacional e o número de unidades de VCL vendidas.

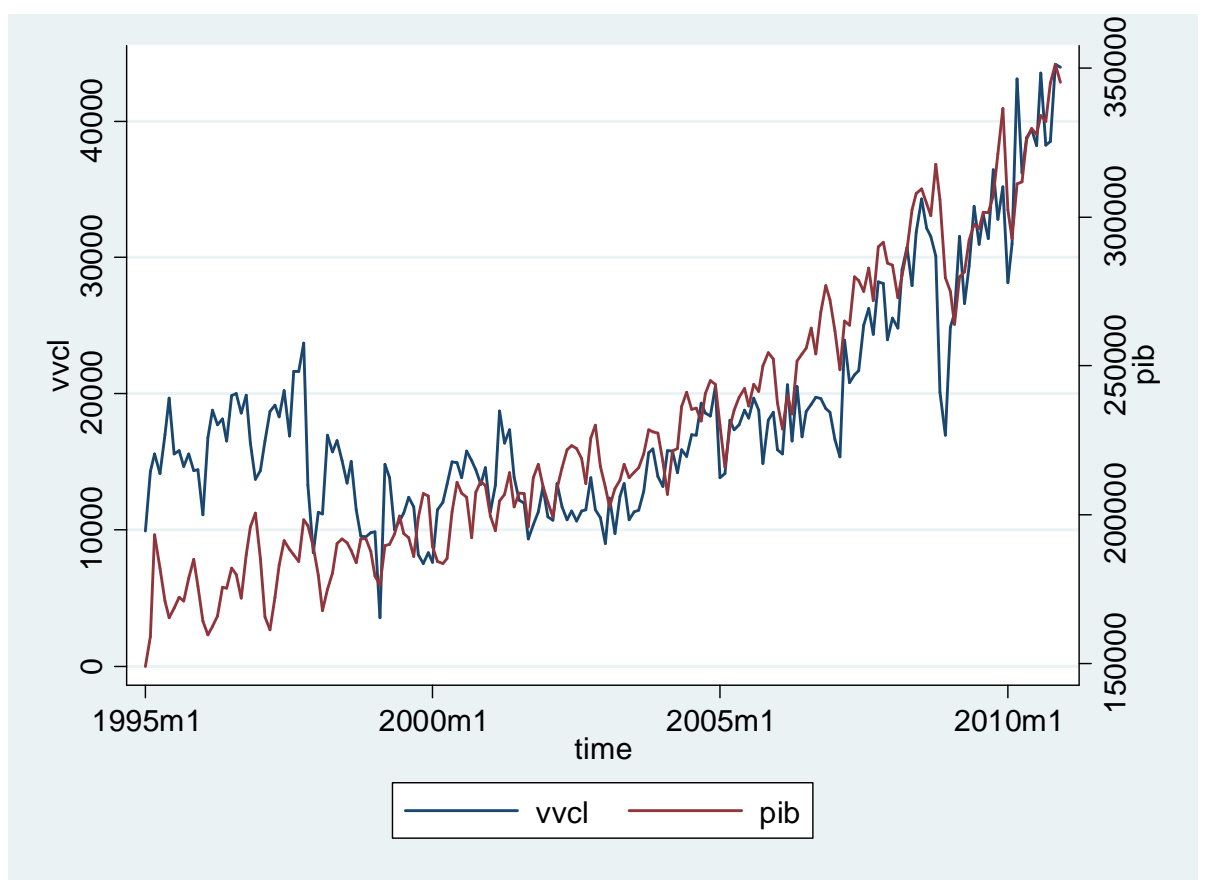

Note que no início da série a correlação não é muito boa. Pode-se atribuir este fato ao período pós-plano Real: com a adoção do câmbio fixo ou administrado. As políticas cambiais adotadas no Plano real até 1999 e questões no âmbito fiscal colaboraram para que as contas 
públicas fossem regularizadas apenas em 1999, coincidência, ou não, é a partir deste período que a série supracitada inicia uma correlação um pouco mais regular.

Em contrapartida, através das Figuras 3 e 4, constata-se que a quantidade de unidades de veículos comerciais leves comercializadas está negativamente correlacionada com a taxa de câmbio e de juros. Percebe-se, nitidamente, que nos períodos de alta cotação do dólar as vendas possuem crescimento desacelerado ou decrescimento. A Figura 5 corresponde às correlações referidas em forma de diagrama de dispersão.

Figura 3 - Correlação negativa entre a quantidade de VCL vendidos e a taxa de câmbio.

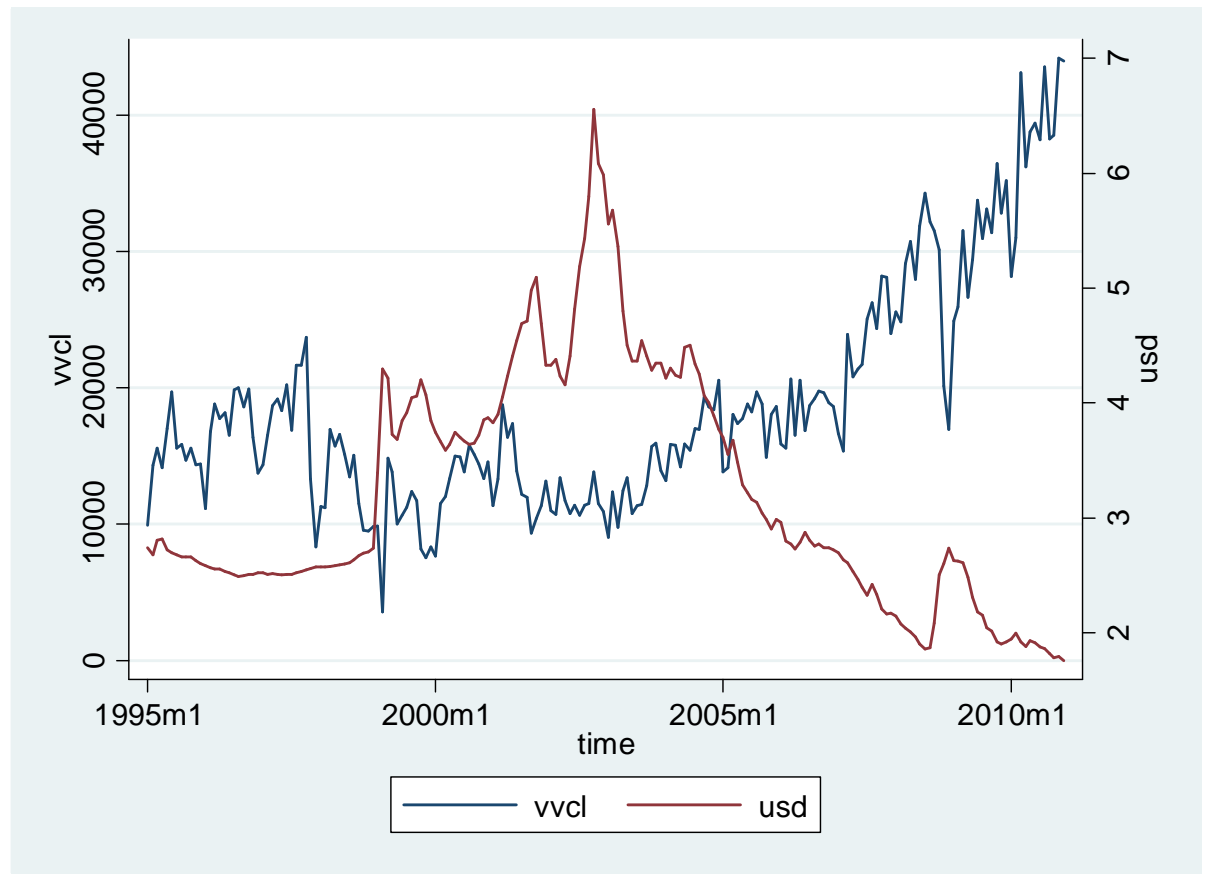

A partir de meados de 2000, a taxa de câmbio vem experimentando um declínio considerável. A principal influência da taxa de câmbio subvalorizada no mercado autoveicular é o crescente número de veículos importados circulando na frota nacional todos os anos. Dados da ANFAVEA apontam que os importados representaram nos quatro primeiros meses deste ano $22,1 \%$ do mercado, ainda segundo a entidade, há uma década dez anos os veículos oriundos de outros países representavam cerca de 5\% dos emplacamentos nacionais.

Estes levantamentos indicam que as barreiras protecionistas incidentes sobre automóveis parecem não ser mais uma boa maneira de contensão na proteção do mercado interno. Dados da ABEIVA mostram que o imposto de importação representa atualmente, em média, $8 \%$ no 
valor final do veículo de origem estrangeira. A exploração de economia de escala e subsídios fornecidos pelos países exportadores são fatores que têm anulado as barreiras tarifárias e exposto o mercados autoveicular à forte concorrência internacional.

Atrelado a estes fatores tem-se que o Brasil experimenta uma taxa de câmbio subvalorizada devido ao intermédio da política de acumulação de reservas proposta pelo BACEN. Quando o BACEN compra reservas, e as esteriliza por intermédio de operações compromissadas, ocorre um aumento da demanda por moeda estrangeira. Possibilitando a produção de uma elevação "artificial" do preço da mesma, induzindo uma taxa real de câmbio subvalorizada. Assim, a política de acumulação de reservas impede, em partes, a valorização natural da taxa real de câmbio, penalizando a manutenção da taxa real de juros em patamares elevados.

Entretanto, parece inevitável que a taxa de câmbio aprecie. Esta mudança cambial tem explicações fundamentadas na trajetória que o Brasil percorre: deixar de ser economia emergente e passar a ser economia desenvolvida. Este é um processo lento que o Brasil está inserido, e a exemplo das experiências internacionais, espera-se que a taxa de câmbio aprecie.

Dados da FIESP (2011) sugerem que a taxa de câmbio de equilíbrio para a indústria está entre $\mathrm{R} \$ 2,00$ e $\mathrm{R}$ \$ 2,20, ou seja, a taxa de câmbio atual está subvalorizada. O cenário atual favorece a entrada dos veículos importados e não acarreta grandes ganhos às exportações brasileiras. Os autores ainda pontuam que a taxa de câmbio de equilíbrio: "não favorece as exportações nem prejudica as importações aumenta a empregabilidade e não tem um impacto tão forte sobre a inflação”.

Este contexto tem favorecido as marcas asiáticas que propõe estratégias agressivas no mercado nacional. Com o intuito de minimizar a concorrência com o mercado nacional há uma linha que a defende a adoção de alíquotas variadas para cada região do mundo. Por exemplo, a tarifa sobre produtos importados, para a região da Ásia, poderia ser de $40 \%$ ou mais, em detrimentos aos $35 \%$ atuais. 
Figura 4 - Correlação negativa entre a quantidade de VCL vendidos e a taxa de juros.

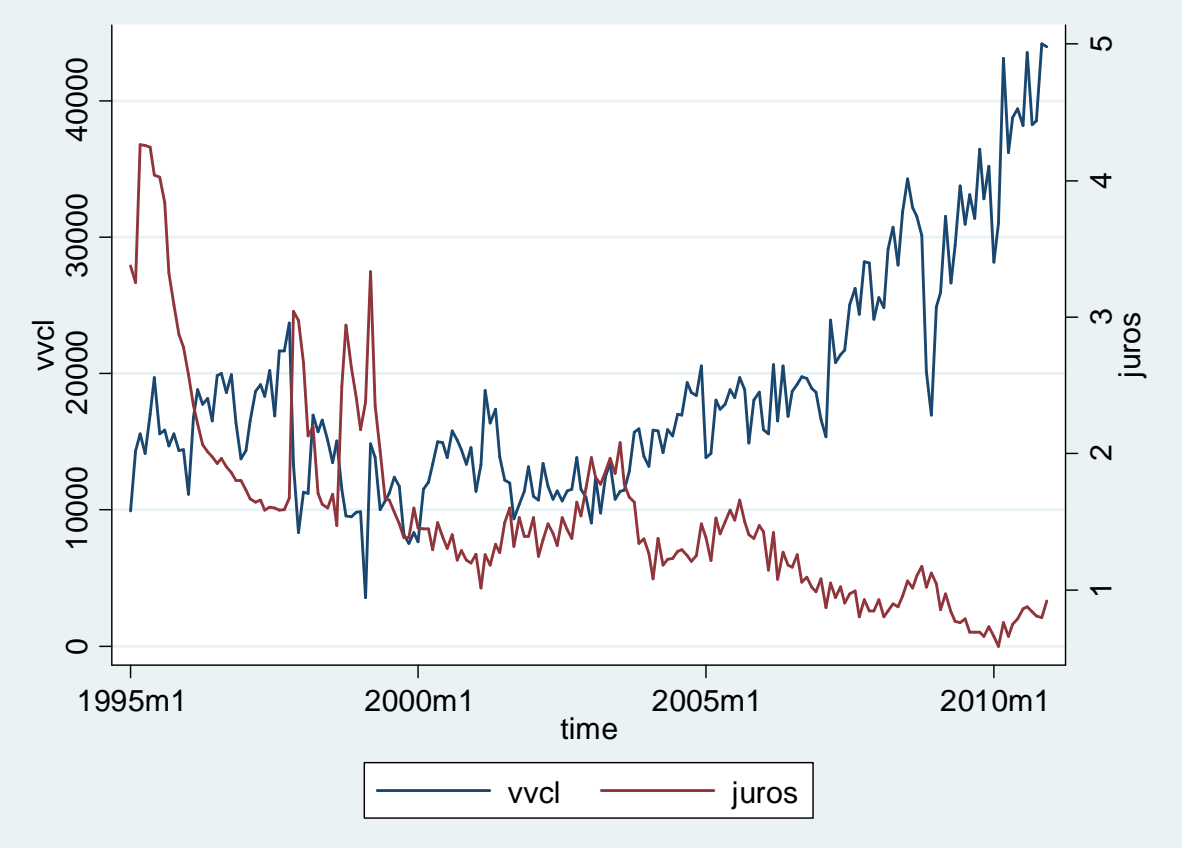

A partir da Figura 3 pode-se notar que o início do governo Lula se caracterizou pela combinação de taxa real de câmbio depreciada e taxa de inflação relativamente alta, ainda que em declínio. Atentando-se ao período pós plano Real, percebe-se uma acentuada curva em declínio, que é efeito da queda na inflação daquele período.

Figura 5 - Correlação das grandezas venda de VCL, PIB e Taxa de câmbio.

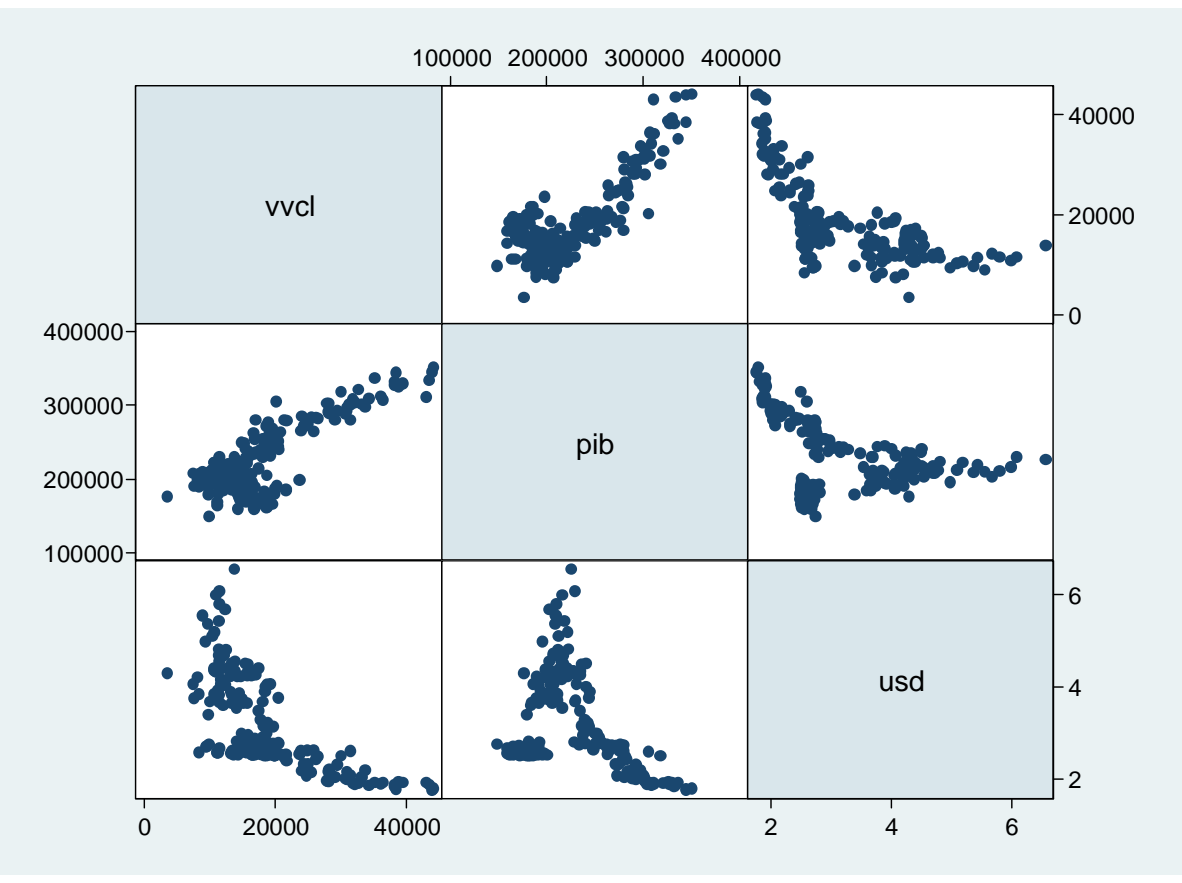




\subsection{Veículos comerciais leves chineses}

A China atual está numa situação similar àquela do Japão na década de 1980: taxa de câmbio subvalorizada e mostrando resistência às pressões internacionais, principalmente dos EUA que visam à flutuação da moeda ao sabor do mercado. Porém, antes de adentrar na problemática propriamente dita, vale levantar uma discussão e responder a seguinte pergunta: por que a China consegue manter uma taxa de câmbio tão subvalorizada e outros países não conseguem?

O regime político ditatorial chinês explica em grande parte esta questão. Um governo autoritário atinge alvos pré-determinados mais facilmente, pois não tem gasto social, rede de proteção social, encargos sobre salários e sindicatos. Desta forma, a China consegue manter ínfimos níveis salariais de mão de obra e concomitantemente a demografia do país facilita manter o salário em níveis baixos. Apesar de o Brasil e a China serem considerados economias emergentes, não se pode importar o modelo cambial chinês para o Brasil, visto que possuímos características políticas, salariais, sindicais e sociais completamente distintas.

A China experimentou no primeiro trimestre de 2010 um crescimento de quase $12 \%$, fato que motivou os EUA a fazerem novas pressões sobre as taxas de juros e a moeda do país. Entretanto, a China afirma que não vai ceder às pressões internacionais sobre a cotação do "yuan". A comunidade internacional, representada pelo imponente EUA, pede para que a moeda chinesa atinja uma taxa de câmbio que "respeitasse mais o mercado". Os líderes norte americanos consideram que a fraca cotação do yuan face ao dólar favorece deslealmente as exportações chinesas.

Vieira (2010) estima que até 2015 o Brasil terá de 20 a 30 milhões de novos consumidores da classe C: o público-alvo das montadoras chinesas. Ele ainda pontua que este aumento de capacidade de consumo deve-se a ampla oferta creditícia, ascensão social, maior participação feminina no mercado de trabalho e incentivos governamentais. Atrelada a esta previsão, outro fator que deve ser analisado para o cômputo do potencial de crescimento do mercado automobilístico brasileiro, é a relação carro/habitante. Segundo a FENABRAVE, este parâmetro é de um carro para 7,9 habitantes, muito aquém da taxa de um carro para cada habitante nos Estados Unidos e Japão. 
As primeiras marcas chinesas a introduzirem seus produtos no mercado brasileiro foram: Chana, Effa Motors e Hafei. A primeira entrante no mercado brasileiro foi a Chana em 2006, que apresentou seus veículos comerciais leves no Salão do Automóvel de São Paulo do mesmo ano. Entretanto as vendas só tiveram início em julho de 2007. Posteriormente, em maio de 2008, a Effa passou a importar a linha de utilitários ULC (comerciais ultraleves) da Hafei, composta de van de passageiros, picape e furgão. Em setembro de 2009, a Chery iniciou as suas operações no Brasil, sem utilitários comerciais leves.

Os comerciais leves tiveram discretos números iniciais de vendas. O volume, somado, em 2010, atinge cerca de 9.000 unidades e representa menos de 0,5\% do mercado nacional. Segundo levantamentos da FENABRAVE, em 2010 a participação chinesa nas vendas totais foi singela, da ordem de 0,33\%, mas cresce ano após ano. Em 2009 era de 0,1\% e, em 2008, de $0,04 \%$. Apesar de representar pouca participação no volume total de venda de autoveículos, todas as montadoras que atuam no setor de automóveis estão também no segmento de VCL. Os pequenos e médios comerciais leves asiáticos aparentam fragilidade, no entanto, têm ganhado, gradativamente, a confiança do consumidor ao oferecer veículos com vários anos de garantia, preços abaixo do mercado e farto pacote de equipamentos de série. A Figura 6 demonstra a ascensão das marcas chinesas no segmento de VCL.

Figura 6 - Unidades de VCL vendidas pelas marcas chinesas Effa, Chana e Hafei de 2009-2010. Fonte: ABEIVA (2010).

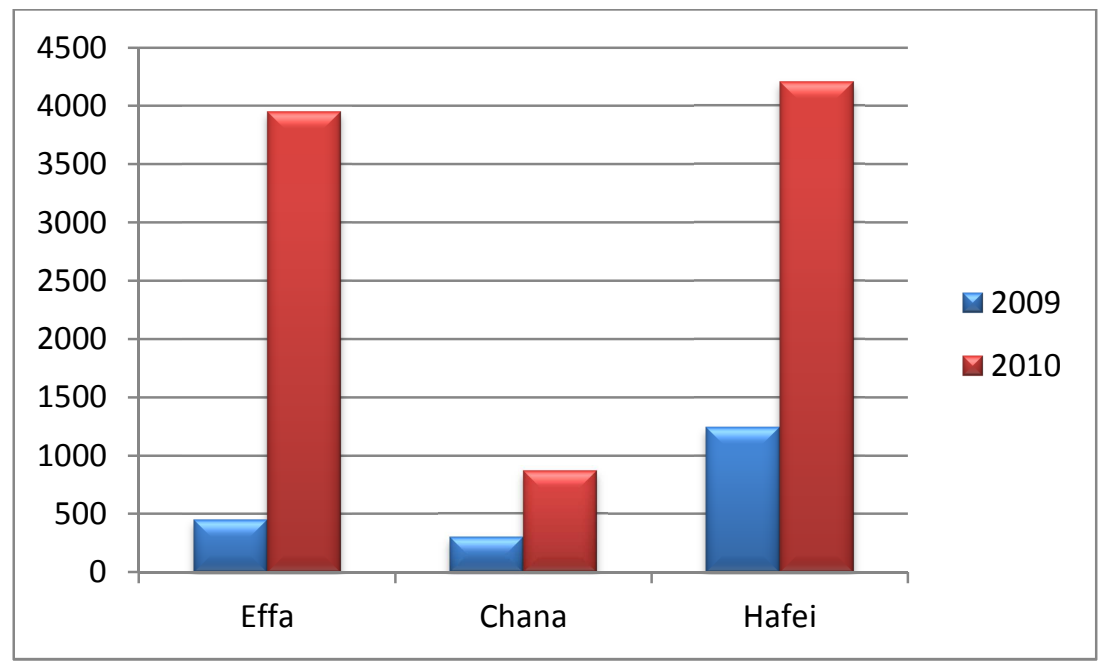


Os chineses, por meio de seus representantes ou filiais aqui buscam preencher lacunas deixadas pela indústria nacional, que ainda hoje não tem produtos específicos para disputar os nichos descobertos pelas marcas novatas. O desinteresse dos fabricantes locais, pelos segmentos que marcas asiáticas focam sua atuação, é atribuído aos baixos volumes atuais de venda, e falta de plataforma. A Tabela 2 evidencia o percentual de crescimento das marcas chinesas e coreanas. Embora, quantitativamente o número de unidades de veículos vendidos coreanos superem os chineses, estes últimos apresentam uma curva mais acentuada de crescimento.

Tabela 2 - Venda de unidades de VCL chineses por marca, período de 2009-2010. Fonte: FENABRAVE (2010).

\begin{tabular}{l|cccc}
\hline & Marca & 2009 & 2010 & \% de crescimento \\
& & & & \\
\hline \multirow{3}{*}{ China } & Effa & 452 & 3953 & 874,5 \\
& Chana & 304 & 868 & 285,5 \\
& Hafei & 1248 & 4207 & 337,1 \\
\hline \multirow{2}{*}{ Korea } & Hyundai HR & 10.871 & 14.860 & 136,7 \\
& Kia Bongo & - & 8480 & - \\
\hline
\end{tabular}

A participação do segmento comercial leve, em 2009, correspondia a $82 \%$ das vendas totais de automóveis chineses, mas em 2010 esta participação diminuiu para 52\%, conforme pode ser obtido da Tabela 3. De fato, o total de VCL chinês era de 2004 (contra um total de 2.437, ou seja, $82 \%$ do total) em 2009, e subiu para 9028 (contra um total de 214.680 , ou seja $52 \%$ do total) em 2010. Explica-se este decréscimo percentual de $82 \%$ para 52\% pelo interesse chinês em conquistar espaço no segmento dos carros de passeio. 
Tabela 3 - Número de unidades vendidas dos VCL Chineses e Coreanos e Percentual de Crescimento. Fonte: FENABRAVE (2010)

\begin{tabular}{l|lll}
\hline No de vendas & 2009 & 2010 & $\begin{array}{c}\% \text { de } \\
\text { crescimento }\end{array}$ \\
\hline VCL Chineses & 2.004 & 9.028 & 450,5 \\
VCL Coreanos & 10.872 & 23.340 & 214,68 \\
Total Chinês & 2.437 & 17.266 & 708,50 \\
& & & \\
\hline
\end{tabular}

\section{Previsão de vendas de veículos comerciais leves}

O volume de venda de veículos comerciais leves foi de 470 mil unidades em 2010. Apresentamos na seção a seguir um estudo econométrico de previsão de vendas para o referido segmento nos anos de 2011-2012.

\subsection{Estudo Econométrico}

Esta seção mostra o modelo econométrico de previsão de venda de veículos comerciais leves no mercado automotivo brasileiro. Em termos de forma funcional, será adotada uma equação linear. Utilizou-se uma regressão múltipla com controle de heteroscedasticidade e correlação. A Tabela 4 apresenta a estatística descritiva das variáveis consideradas na modelagem:

- vvcl - unidades de veículos comerciais leves nacionais vendidas. ANFAVEA (fonte: IPEADATA)

- pib - produto interno bruto (Banco Central) deflacionado pelo IPCA (fonte: IBGE)

- usd - taxa de câmbio (IPEADATA) deflacionada pelo IPCA (fonte: IBGE)

- juros - taxa de juros - Over / Selic - (\% a.m.) - Banco Central do Brasil, Fonte: IPEADATA.

- $\quad \mathrm{m} \_n$ - variável binária (dummy) indicativa de mês do ano. Por exemplo: m_1 indica o mês de janeiro. 
- p_veicnovo - índice de preço médio de aquisição de Automóvel novo. Fonte: IBGE/IPCA (média do período = 100)

Tabela 4 - Estatística descritiva das variáveis inclusas no modelo econométrico.

\begin{tabular}{lllll}
\hline Variável & Média & $\begin{array}{l}\text { Desvio- } \\
\text { Padrão }\end{array}$ & Mínimo & Máximo \\
\hline vvcl & 18557.04 & 8203.942 & 3356 & 44140 \\
pib & 229016 & 47826.6 & 149098.8 & 351111 \\
& & & & \\
usd & 3.201013 & 1.028772 & 1.758307 & 6.558112 \\
& & & & \\
p_veicnovo & 91 & 11.8 & 64,2 & 118.2 \\
\hline
\end{tabular}

Os resultados do modelo econométrico estão apresentados na Tabela 5. O resultado econométrico mostra coerência nos sinais e nas amplitudes das estimativas, associados a um baixo p-valor. Em geral, a grande maioria das variáveis de interesse apresentou coeficiente estimado que era, ao mesmo tempo, estatisticamente significante ao nível de $1 \%$ e com o sinal consistente com o esperado, com exceção da variável juros que além de mostrar-se estatisticamente insignificante, apresentou sinal positivo, incoerente com o efetivo comportamento de compra do consumidor, portanto não permite auferir quaisquer inferência causal. A correlação positiva entre pib e vvcl, que era intuitivamente esperada, de fato permaneceu no modelo econométrico. 
Tabela 5 - Resultados do modelo de previsão de vendas de VCL nacionais.

\begin{tabular}{|c|c|c|c|}
\hline Variável & $\operatorname{simp} 1$ & simp3 & $\operatorname{simp} 4$ \\
\hline pib & $.141 * * * .113 * * *$ & $.114 * * *$ & $.115^{* * *}$ \\
\hline usd & $-3268 * * *$ & $-3255 * * *$ & $-3237 * * *$ \\
\hline juros & & 80.9 & \\
\hline $\mathrm{m} \_2$ & & & $2266 * * *$ \\
\hline m_3 & & & $5170 * * *$ \\
\hline m_4 & & & $3148 * * *$ \\
\hline m_5 & & & $2794 * * *$ \\
\hline m_6 & & & $2812 * * *$ \\
\hline $\mathrm{m}_{-} 7$ & & & $2693 * * *$ \\
\hline m_8 & & & $3812 * * *$ \\
\hline m_9 & & & $3469 * * *$ \\
\hline $\mathrm{m} \_10$ & & & $2715^{* *}$ \\
\hline $\mathrm{m} \_11$ & & & 579 \\
\hline $\mathrm{m} \_12$ & & & 440 \\
\hline$-13734 * * *$ & 3105 & 2715 & 146 \\
\hline $\mathrm{R}^{2}$ ajustado .674 & .815 & .814 & .837 \\
\hline
\end{tabular}

Legenda: $* \mathrm{p}<.1 ; * * \mathrm{p}<.05 ; * * * \mathrm{p}<.01$ 


\subsection{Projeção de demanda}

A previsão de vendas de veículos comerciais leves baseou-se nas projeções de crescimento de PIB. Considerou-se, num primeiro plano, um cenário base em que o produto interno bruto cresceria às taxas anuais de 4\% e 4,1\% respectivamente em 2011 e 2012. Em uma segunda instância, considerou-se um cenário otimista com crescimento do PIB à taxa de 7,2\% a.a. Apesar de julgar conservadoras estas expectativas de crescimento, optou-se por não utilizar "benchmarks" mais elevados devido aos impactos das medidas tomadas pelo governo para frear o consumo sobre a comercialização de veículos impostos pelo Banco Central do Brasil como mecanismo de contensão inflacionária. As estimativas finais de venda de VCL estão dispostas na tabela 8 , a seguir.

Tabela 6 - Previsões de unidades de veículos comerciais leves nacionais vendidas e percentual de crescimento em relação a 2010.

\begin{tabular}{lllllll}
\hline Período & Cenário Base & $\begin{array}{c}\% \text { em relação a } \\
2010\end{array}$ & $\begin{array}{l}\text { Cenário } \\
\text { Otimista }\end{array}$ & $\begin{array}{l}\% \text { em relação a } \\
2010\end{array}$ \\
\hline 2011 & 559.448 & $20,8 \%$ & 577.034 & $24,6 \%$ \\
2012 & 582.948 & $25,9 \%$ & 618.441 & $33,6 \%$ \\
\hline
\end{tabular}

Se por um lado temos as medidas governamentais, como a elevação do depósito compulsório das entidades financeiras para diminuir o volume de crédito no mercado e controlar o aumento da inflação. Estas medidas visam diminuir o consumo, por isto racionalmente espera-se um crescimento irrisório para o ano de 2011. Contraditoriamente, levantamentos da FENABRAVE registram recorde de vendas no primeiro quadrimestre deste ano em relação ao mesmo período de 2010. Nem mesmo as medidas regulatórias do governo parecem prejudicar a viabilidade econômica dos fabricantes de veículos. Este fato comprova que o mercado de autoveículos está "superaquecido", registrando recordes de vendas, ano após ano, e as crises econômicas e a inflação, tem surtido pouco efeito sobre o volume de vendas destes bens duráveis. 


\section{Conclusão}

Este artigo tem como objetivo avaliar a dimensão atual do mercado brasileiro de autoveículos, com ênfase na classe de veículos comerciais leves (VCL): veículos que possuem peso bruto total, de até 3,5 toneladas, englobam desde as pick-ups pequenas, até os furgões, vans, e utilitários esportivos. O segmento caracterizou a porta de entrada que possibilitou a internacionalização das marcas chinesas em meados de 2006. O estudo econométrico demonstra que a frota brasileira contará com mais um milhão e duzentos mil veículos desta categoria - o que, em termos percentuais representa um crescimento de $6 \%$ anualmente $\mathrm{O}$ volume de vendas de VCL chineses tem evoluído à taxas mais elevadas, da ordem de $450 \%$ a.a., superior a média de crescimento das rivais coreanas.

Do ponto de vista das políticas públicas, há relevância no estudo desta classe, em especial, pois compõe um setor que está em franca ascensão, e num futuro próximo pode tornar-se um gargalo para as infraestruturas viárias e seus desdobramentos. Portanto, fornece embasamento para o fomento de políticas públicas acerca do planejamento de transportes urbano e emissões veiculares de poluentes nos grandes centros.

A China tem experimentado crescimentos anuais superiores a 10\%. Explica-se em parte esta ascensão devido a fraca cotação do "yuan" face ao dólar que tem favorecido deslealmente as exportações chinesas além da mão de obra barata, e dos ganhos em produção de escala.

O cenário global está reorganizando suas forças na indústria automobilística através da transferência do potencial de produção e consumo de automóveis para os países emergentes em especial na China, Índia e Brasil. Os fabricantes chineses possuem uma oportunidade verossímil de assegurar confortavelmente a liderança na produção e comercialização de automóveis, posicionando estrategicamente o mercado brasileiro para alavancar a rentabilidade de suas operações.

Caracteriza-se assim um cenário favorável para a expansão da indústria automobilística chinesa com profundas implicações nos mercados ocidentais. O crescente número de marcas, a diversidade de produtos oferecidos, a ampliação dos segmentos de atuação corroboram com a idéia de que a chegada dos veículos comerciais leves asiáticos consiste numa ameaça à 
hegemonia das grandes marcas, de forma natural a participação de mercado das montadoras tradicionais diminuirá, devido ao aumento da concorrência destes novos entrantes.

Ainda que a participação dos veículos comerciais leves no montante de unidades chinesas comercializadas diminua, as novas entrantes sinalizam uma ameaça ao market share das empresas dominantes, pois demonstram o interesse dos asiáticos pelas categorias de veículos em que já há ampla concorrência, como o segmento pioneiro dos carros de passeio.

Há fortes indícios de que a participação dos chineses aumente no setor de autoveículos. Talvez o principal deles baseia-se na sub-valorização da taxa de câmbio nacional. A principal influência da sub-valorização da taxa de câmbio no mercado autoveicular é o crescente número de veículos importados circulando na frota nacional todos os anos. Dados da ANFAVEA apontam que os importados representaram nos quatro primeiros meses deste ano $22,1 \%$ do mercado, ainda segundo a entidade, há uma década dez anos os veículos oriundos de outros países representavam cerca de $5 \%$ dos emplacamentos nacionais. Estes levantamentos indicam que nem mesmo as barreiras protecionistas (alíquotas) incidentes sobre automóveis parecem surtir efeito na contensão na proteção do mercado interno.

\section{Referências}

ABEIVA (2010) Estatísticas da Associação Brasileiras das Empresas Importadoras de Veículos Automotores. Disponível para download em www.ABEIVA.com.br

ANFAVEA (2010) Anuário da Indústria Automobilística Brasileira de 2010. Disponível para download em www.ANFAVEA.com.br

BACEN (2010) Banco Central do Brasil. Disponível em www.bacen.gov.br.

CSM Worldwide, Inc. Previsão de Mercado Automotivo. Disponível para download em http://pt.csmauto.com/

DENATRAN (2010) Estatísticas das frotas. Disponível para download em www.denatran.gov.br

FENABRAVE (2009) Anuário Estatístico de 2009. Disponível para download em www.FENABRAVE.com

FIEB (2010) Estatísticas da Federação das Indústrias do Estado da Bahia. Disponível em www.fieb.org.br

Fiúza, E. (2002) Automobile Demand And Supply In Brazil: Effects Of Tax Rebates And Trade Liberalization On Price-Marginal Cost Markups in the 1990s. Texto para Discussão - IPEA, $\mathrm{n}$. 916.

OICA (2010) Production Statistics. Disponível para download em http://www.oica.net/ 
Paiva, C. (2011) Evolução dos tempos das viagens do modo trem na Região Metropolitana de São Paulo. Journal of Transport Literature, vol. 5, n. 3, pp. 182-191.

Paiva, C. (2013) Atendimento à população: ônibus urbano no município de São Paulo. Journal of Transport Literature, Vol. 7, n.1.

Ramis, J. E. e Santos, E. A. (2012) Uso de automóveis e o caos urbano - considerações sobre o planejamento de transportes das grandes cidades. Journal of Transport Literature, Vol. 6, n.4.

Vieira, V. L. R. (2010) A internacionalização da indústria automobilística chinesa: as consequências para o comportamento do consumidor brasileiro. Relatório de Pesquisa da Pontifícia Universidade Católica. 